Article

\title{
Immobilization of Stabilized Gold Nanoparticles on Various Ceria-Based Oxides: Influence of the Protecting Agent on the Glucose Oxidation Reaction
}

\author{
Meriem Chenouf ${ }^{1,2}$, Cristina Megías-Sayago ${ }^{1}$, Fatima Ammari $^{2}$, Svetlana Ivanova ${ }^{1}$, \\ Miguel Angel Centeno ${ }^{1, *(D)}$ and José Antonio Odriozola ${ }^{1}$ (D) \\ 1 Departamento de Química Inorgánica e Instituto de Ciencia de Materiales de Sevilla, \\ Universidad de Sevilla-CSIC, Américo Vespucio 49, 41092 Sevilla, Spain; meriemc94@gmail.com (M.C.); \\ cristina.megias@icmse.csic.es (C.M.-S.); svetlana@icmse.csic.es (S.I.); odrio@us.es (J.A.O.) \\ 2 LGPC, Department of chemical process engineering, Ferhat-Abbas Sétif-1 University, Sétif 19000, Algeria; \\ ammarifatima@yahoo.fr \\ * Correspondence: centeno@icmse.csic.es
}

Received: 31 December 2018; Accepted: 17 January 2019; Published: 31 January 2019

check for updates

\begin{abstract}
The influence of the protecting agent's nature on gold particle size and dispersion was studied in this work over a series of gold-based catalysts. CO and glucose oxidation were chosen as catalytic reactions to determine the catalyst's structure-activity relationship. The nature of the support appeared to be the predominant factor for the increase in activity, as the oxygen mobility was decisive for the $\mathrm{CO}$ oxidation in the same way that the Lewis acidity was decisive for the glucose oxidation. For the same catalyst composition, the use of montmorillonite as the stabilizing agent resulted in better catalytic performance.
\end{abstract}

Keywords: gold nanoparticles; clay; PVA; stabilizing agent; glucose oxidation

\section{Introduction}

The use of renewable feedstocks to produce platform chemicals as an alternative to the classical petrochemical route is attracting more and more scientific attention [1,2]. The number of possibilities to convert lignocellulosic biomass into value-added chemicals is continuously increasing, focusing the research interest on this topic. New technologies have arisen, but the majority of these processes are still under investigation. One example of such a process is the production of gluconic acid, industrially available as an enzymatically catalyzed process. It is a process with great potential to become a heterogeneously catalyzed process in the future [3-5]. Gluconic acid and its salts are extensively used as detergents, food and beverage additives, and intermediates for the pharmaceutical and cosmetic industries [6,7]. Glucose to gluconic acid conversion goes through selective oxidation of the aldehyde function in anomeric position (C1), where all other alcoholic groups (C2-C6) must remain unaltered. Therefore the choice of a robust and highly selective catalyst is crucial to avoid side products [8].

Gold catalysts are often reported to be good candidates for oxidation reactions due to their remarkable oxidation ability and resistance to oxygen poisoning [9]. In a liquid phase, gold catalysts are especially useful, making it possible to use cheap and non-corrosive oxidants (air instead of $\mathrm{KMnO}_{4}$ or $\mathrm{H}_{2} \mathrm{O}_{2}$ ) [10,11]. Gold catalysts are, in fact, reported to be promising for the selective production of gluconic acid [12-15].

Although they are very stable and effective in the presence of a base [16], gold catalysts deactivate rapidly in base-free conditions due principally to metal leaching and sintering [12]. The base-free conditions present some advantages and are highly desirable from a technological point of view. They are based on green chemistry principles and present some economic advantages due to the absence of 
time and money spent on reaction steps, such as gluconate salt separation and conversion to acid. This is why the most important requisite for using gold catalysts is to improve their stability in base-free conditions. For this purpose, the use of nanoparticle stabilizing agents, or a highly specific surface support could be useful to prevent both gold leaching and sintering.

On the other hand, nanoparticle homogeneity is of great importance to establish a correlation between catalytic activities, the nature of the active species, support and their interactions. Although several methods for the preparation of gold catalysts have been reported, the gold colloidal route seems to be one of the most appropriate to obtain homogeneous and reproducible gold nanoparticle size distribution. This route includes the utilization of stabilizing agents influencing the nucleation/growth mechanisms during the nanoparticle formation process. The stabilization of gold nanoparticles (AuNPs) can be achieved using surfactants [17], polymers [18,19] and metal oxides [20-22].

Recently, clay minerals have been reported as stabilizing agents of nanoparticles [23,24]. Clay minerals are natural materials that are environmentally benign, costless and abundant. They are largely used as sorbents [25,26] or in catalysis, for glycerol dehydration [27] and aromatic hydrocarbon production [28]. Their use as support for gold nanoparticles is also reported [28-32].

In this study, two different agents were used to stabilize gold nanoparticles prepared by the colloidal route, i.e. clay (montmorillonite (Mt)) and polymer (polyvinyl alcohol (PVA)). The catalytic performance in $\mathrm{CO}$ and glucose oxidation reactions of those nanoparticles immobilized over a series of supports were used to determine the influence of the stabilizing agent on gold particle size, dispersion and activity.

\section{Results and Discussion}

The specific surface areas, particle size and gold contents are reported in Table 1. A total of 25 to $50 \%$ of gold loss is observed within the series and it is hardly related to the nature of the supports and/or the specific surface area. Nevertheless, it could be explained by the stability of the gold colloids, depending on the nature of the protecting agent. The higher the stability of the colloids, the lower the quantity of gold deposited during the immobilization. It appears that PVA as a "liquid state" stabilizing agent (polymer completely dissolved within the media) helps particle adsorption and results in a higher final gold loading. As for the Mt stabilizer, the higher gold loss could be assigned either to a greater colloid stabilization or to a decrease of the metal adsorption rate caused by the changes produced in the isoelectric point of the supports with the addition of the clay material. The use of clays as the stabilizers of gold particles is also prone to higher experimental errors due to the delicate execution of the procedure.

Table 1. Catalysts metal loadings and structural properties.

\begin{tabular}{|c|c|c|c|c|c|}
\hline Samples & $\begin{array}{c}\text { Au Loading, } \\
\text { wt. } \%\end{array}$ & $\begin{array}{c}\text { BET } \\
\left(\mathrm{m}^{2} / \mathrm{g}\right)\end{array}$ & $\begin{array}{l}\text { Pore Size } \\
\quad(\mathrm{nm})\end{array}$ & $\begin{array}{l}\text { Pore Volume } \\
\quad\left(\mathrm{cm}^{3} / \mathrm{g}\right)\end{array}$ & $\begin{array}{c}\text { Mean Particle Diameter } \\
\text { dp(nm) TEM } \\
\pm 1.2\end{array}$ \\
\hline $\mathrm{CeO}_{2}$ & - & 137 & 6.5 & 0.23 & - \\
\hline $\mathrm{Au}-\mathrm{Mt} / \mathrm{Ce}$ & 1.5 & 128 & 6 & 0.21 & $4\left(6.8^{*}\right)$ \\
\hline $\mathrm{Au}-\mathrm{PVA} / \mathrm{Ce}$ & 1.6 & 137 & 5.5 & 0.21 & $3.9\left(7^{*}\right)$ \\
\hline $50 \mathrm{Ce} 50 \mathrm{Zr}$ & - & 55 & 11 & 0.18 & - \\
\hline $\mathrm{Au}-\mathrm{Mt} / 50 \mathrm{CeZr}$ & 1.2 & 50 & 10.4 & 0.16 & 5.1 \\
\hline Au-PVA/50CeZr & 2.2 & 47 & 10.6 & 0.15 & 5.7 \\
\hline $20 \mathrm{CeAl}$ & - & 186 & 6.9 & 0.42 & - \\
\hline $\mathrm{Au}-\mathrm{Mt} / 20 \mathrm{CeAl}$ & 1 & 168 & 7.7 & 0.36 & 5.6 \\
\hline Au-PVA/20CeAl & 1.7 & 154 & 8.1 & 0.37 & 5.7 \\
\hline
\end{tabular}

The The Brunauer-Emmett-Teller (BET)-specific surface areas of the catalysts were similar to those of the corresponding supports. The use of different stabilizing agents did not significantly influence this parameter. All samples were mesoporous solids with a pore size within the $5-10 \mathrm{~nm}$ range and pore total volume increasing in order $50 \mathrm{CeZr}<\mathrm{Ce}<20 \mathrm{CeAl}$. 
XRD analysis of all samples, as seen in Figure 1, showed the presence of one dominating phase, the cubic fluorite $\mathrm{CeO}_{2}$ structure (JCPDS \#00-034-0394). With the addition of $\mathrm{Zr}$ (50CeZr sample), the fluorite diffractions shifted to higher $2 \theta$ angles, an effect caused by the formation of a solid solution. The shift is also indicative of the ceria lattice contraction due to the replacement of $\mathrm{Ce}^{4+}$ ( $0.098 \mathrm{~nm}$ ionic radii) with smaller $\mathrm{Zr}^{4+}$ cations $(0.084 \mathrm{~nm})$. Thus, the observed diffractions for this sample corresponded to the cubic Ce-Zr solid solution (JCPDS \#00-028-0271). For the 20CeAl sample, the presence of g- alumina (JCPDS \#00-048-0367) was also detected.
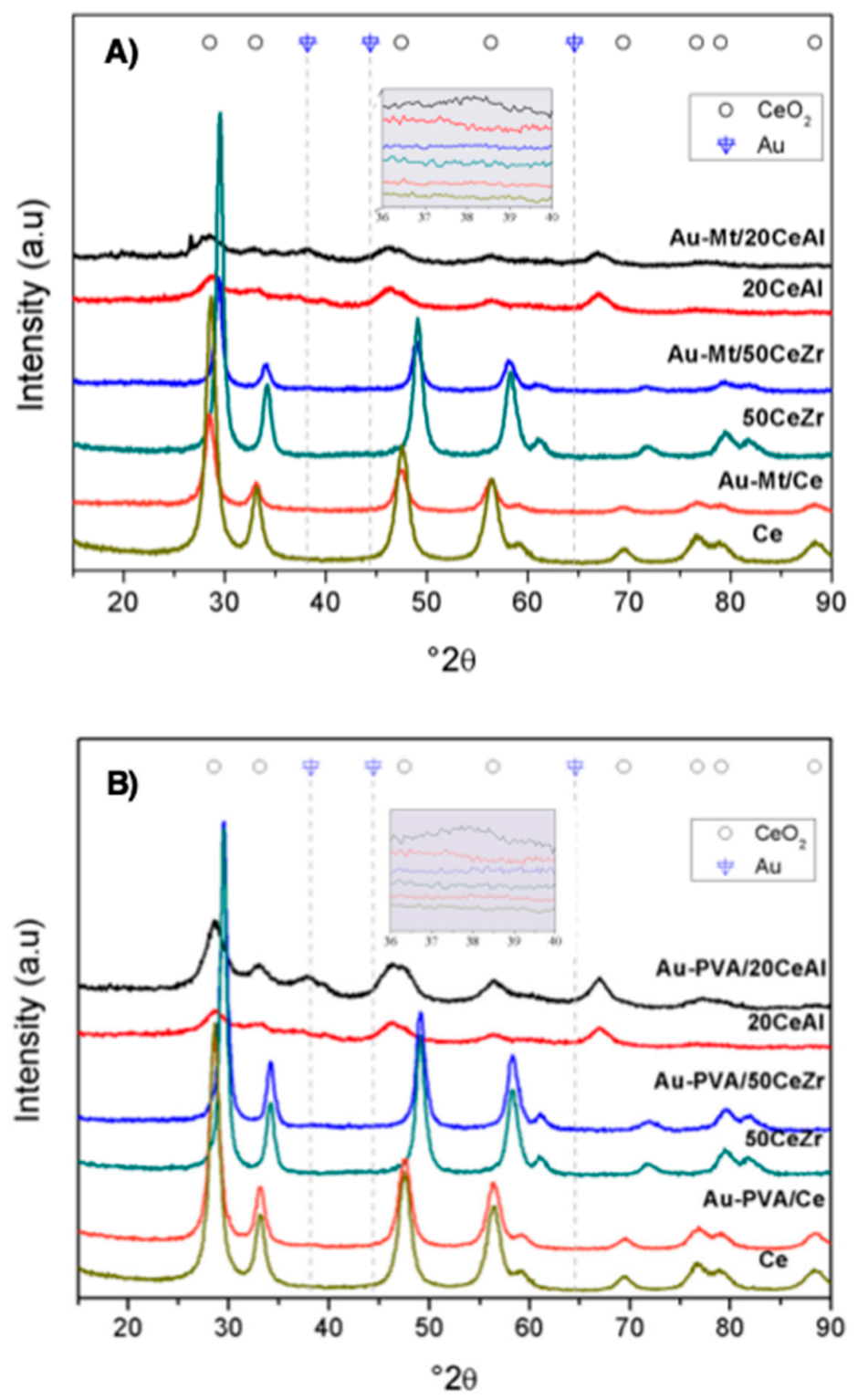

Figure 1. X-Ray diffractograms of supports and catalysts: (A) Mt- and (B) Polyvinylalcohol (PVA)-protected solids, insets zoom on Au (111) diffraction.

For all clay-stabilized samples, the presence of Mt was not evident, probably due to the high intensity of the ceria phase diffractions. Nevertheless, for the 20CeAl support two additional diffractions at 19 and $26^{\circ} 2 \mathrm{Q}$ appeared, which could be attributed to the Mt phase but also to g-alumina.

For the catalysts, diffractions corresponding to gold phases were not detected, suggesting an average gold particle size inferior to $4 \mathrm{~nm}$. The in-zone XRD analysis (36-40 $2 \theta$ range) also suggested important gold dispersion. Only for the $\mathrm{Au} / 20 \mathrm{CeAl}$ catalyst did a diffraction situated at the typical angle of $\mathrm{Au}(111)$ plane appear, but it could also be ascribed to the overlapping g-alumina phase. 
A)
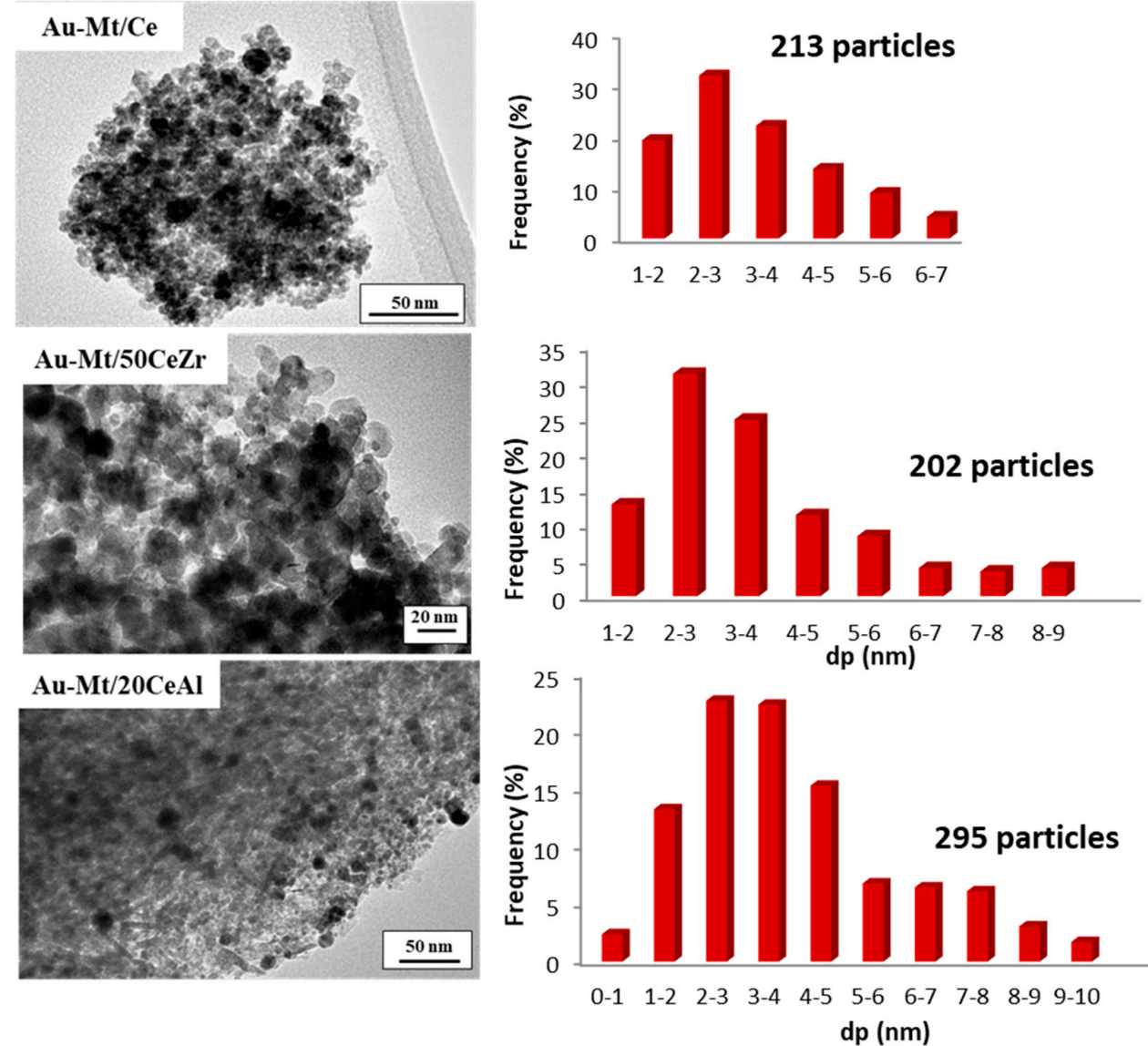

B) Au-PVA/Ce
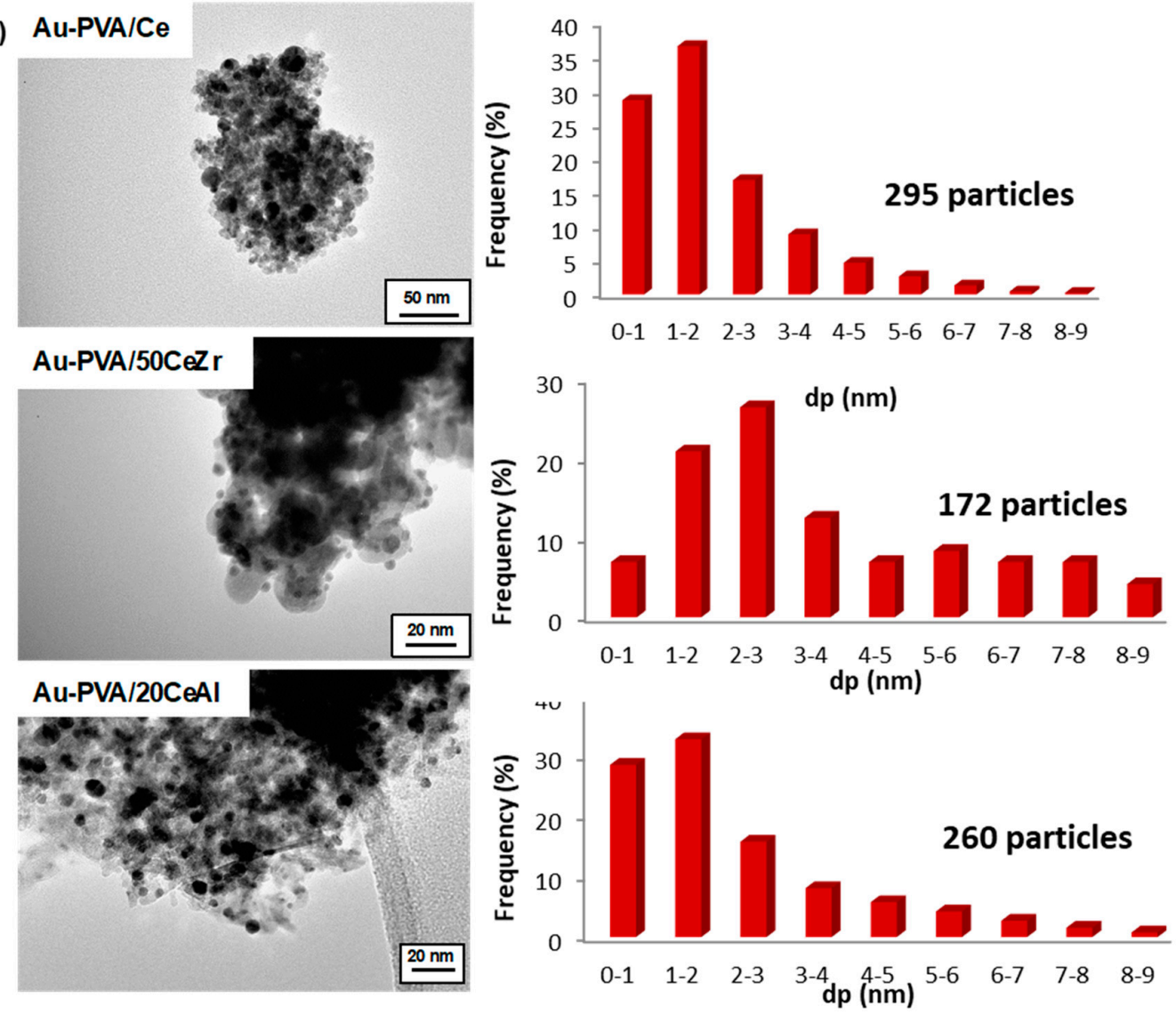

Figure 2. TEM micrographs and particle size distributions of (A) Mt- and (B) PVA-solids. 
The TEM analysis, seen in Figure 2, showed that the calculated average particle size, seen in Table 1, was not affected by the stabilizing agent but by the support. The gold particles were smaller on the bare ceria support than on its mixed analogues.

The reaction of $\mathrm{CO}$ oxidation is often described as very sensitive to the gold metal state (loadings and dispersion) and to the nature of the support [33,34]. The $\mathrm{CO}$ oxidation activity in terms of the light off conversion curves is presented in Figure 3.
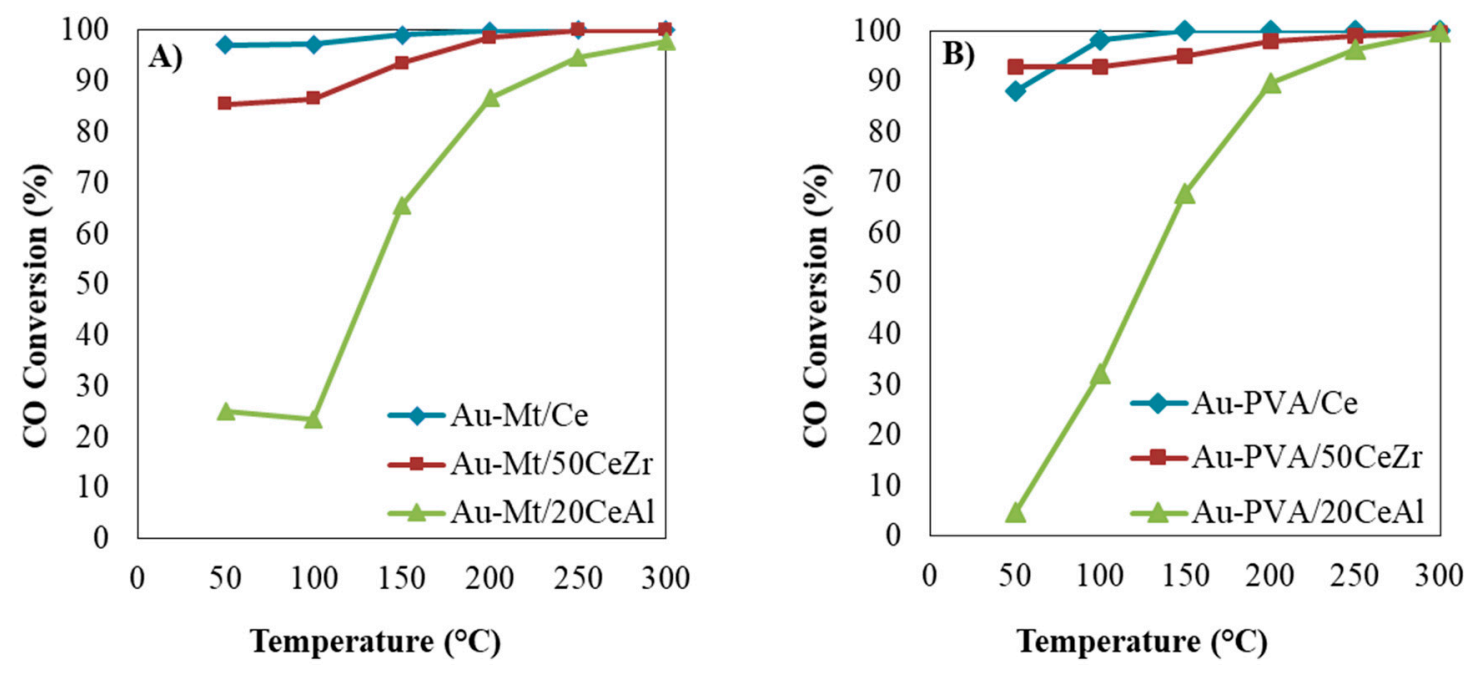

Figure 3. CO conversion (\%) over (A) Mt-solids and (B) PVA-solids.

It was observed that the activity was especially influenced by the support composition. Whereas the Ce and 50CeZr-supported samples attained almost full conversion at the lowest temperature of measurement, the 20CeAl-supported catalyst was active at a higher temperature, regardless of the stabilizing agent. Taking into account the different gold loadings and dispersion for every catalyst, a normalization of the catalytic activity was made for comparison. The specific activity was expressed in millimoles of CO converted per gram of catalyst and second, as well as the turnover frequency (TOF), which was defined as the number of moles of $\mathrm{CO}$ converted per mole of surface gold atom and second, were calculated for all samples at $50{ }^{\circ} \mathrm{C}$. The results are summarized in Table 2 . The required dispersion was calculated using the mathematical model for cuboctahedral particles [35,36], which is also presented in Table 2.

Table 2. Catalyst' specific activity and gold particles dispersion.

\begin{tabular}{|c|c|c|c|c|}
\hline Sample & $\begin{array}{c}\text { Specific Reaction Rate, } \\
\text { mmolesCO }_{\text {conv }} \cdot \mathrm{g}_{\text {cat }}{ }^{-1} \cdot \mathrm{s}^{-11}\end{array}$ & $\begin{array}{l}\text { TOF(CO), } s^{-11} \\
\quad \times 10^{2}\end{array}$ & $\begin{array}{l}\text { TOF(Glucose) } \\
\times 10^{3}, \mathrm{~s}^{-11}\end{array}$ & Dispersion \\
\hline $\mathrm{Au}-\mathrm{Mt} / \mathrm{Ce}$ & 0.69 & 41.3 & 4.7 & 0.32 \\
\hline $\mathrm{Au}-\mathrm{PVA} / \mathrm{Ce}$ & 0.58 & 34.4 & 3.8 & 0.33 \\
\hline $\mathrm{Au}-\mathrm{Mt} / 50 \mathrm{CeZr}$ & 0.77 & 58.5 & 6.3 & 0.26 \\
\hline $\mathrm{Au}-\mathrm{PVA} / 50 \mathrm{CeZr}$ & 0.45 & 37.9 & 3.9 & 0.23 \\
\hline Au-Mt/20CeAl & 0.13 & 10.5 & 8.5 & 0.23 \\
\hline $\mathrm{Au}-\mathrm{PVA} / 20 \mathrm{CeAl}$ & 0.031 & 2.6 & 6.5 & 0.23 \\
\hline $\mathrm{Au} / \mathrm{Ce}[13]$ & - & - & 1.7 & 0.33 \\
\hline $\mathrm{Au} / 20 \mathrm{CeAl}[13]$ & - & - & 2.6 & 0.38 \\
\hline $\mathrm{Au} / 50 \mathrm{CeZr}[13]$ & - & - & 1.6 & 0.38 \\
\hline
\end{tabular}

The normalization of the activity by the active phase loading (specific activity) and dispersion (TOF) presents the same main trend. It is clear that the catalyst activity depends on the nature of both the support and the stabilizing agent. However, the predominant factor is the nature of the support, over catalytic activity. The CO oxidation over ceria-based catalysts proceeds via the Mars van Krevelen mechanism, where the support participates in the reaction, supplying active oxygen species. 
The increase in oxygen mobility, reported to occur with $\mathrm{Zr}$ addition $[37,38]$, results in a better catalyst $(\mathrm{Au} / \mathrm{Ce} 50 \mathrm{Zr}>\mathrm{Au} / \mathrm{Ce}>\mathrm{Au} 20 \mathrm{CeAl})$. As long as the ceria surface oxygen is accessible and abundant, the catalyst activity is higher.

As for the nature of the stabilizing agent, the use of $\mathrm{Mt}$ is more important than the use of polymer (PVA). A few probable causes for this, is the existence of some carbonaceous residues after the calcination procedure, a change of the gold-support interaction in the presence of organic agents and/or the electronic effect of metal. A more detailed study is needed to distinguish between the causes. Contrary to a gas phase reaction (CO oxidation), where the oxidant is continuously renewed, the liquid phase oxidation (glucose oxidation) depends on the concentration of dissolved oxygen in the media, which is more affected by the pressure than by the temperature. Higher partial pressures and lower temperatures promote a full glucose conversion. In order to observe and evaluate the real effect of the stabilizing agent and support nature, we decided to decrease the conversion by using higher temperatures and atmospheric pressure. The temperature did not affect the glucose conversion over the Au-Mt/Ce catalyst (Figure 4), but produced interesting changes in selectivity. An increase in the temperature promoted lactic acid formation, disfavoring the glucose to fructose reaction. Both products affected the gluconic acid selectivity, with the best activity/selectivity ratio observed at $100{ }^{\circ} \mathrm{C}$.
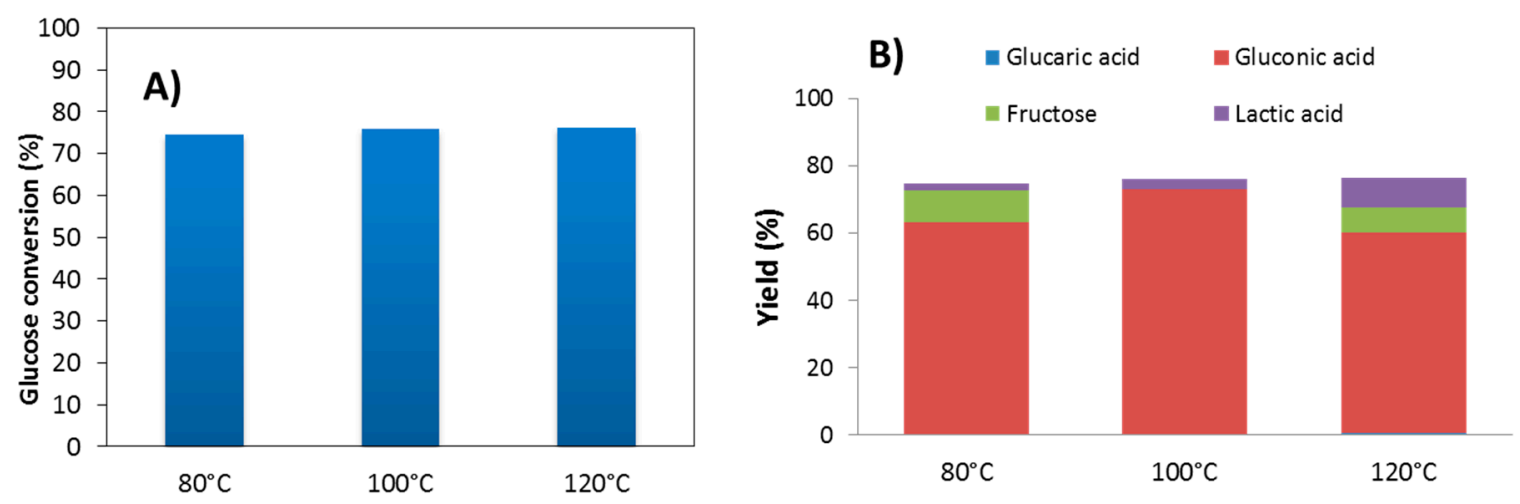

Figure 4. (A) Glucose conversion (\%) as a function of the temperature over Au-Mt/Ce (600 rpm, $18 \mathrm{~h})$; (B) yield (\%).

As the major changes in selectivity occurred at $120^{\circ} \mathrm{C}$, this temperature was chosen for all other experiments. The glucose conversion and calculated TOF at the final time of the reaction $(18 \mathrm{~h})$ are summarized in Figure 5 and Table 2, respectively.
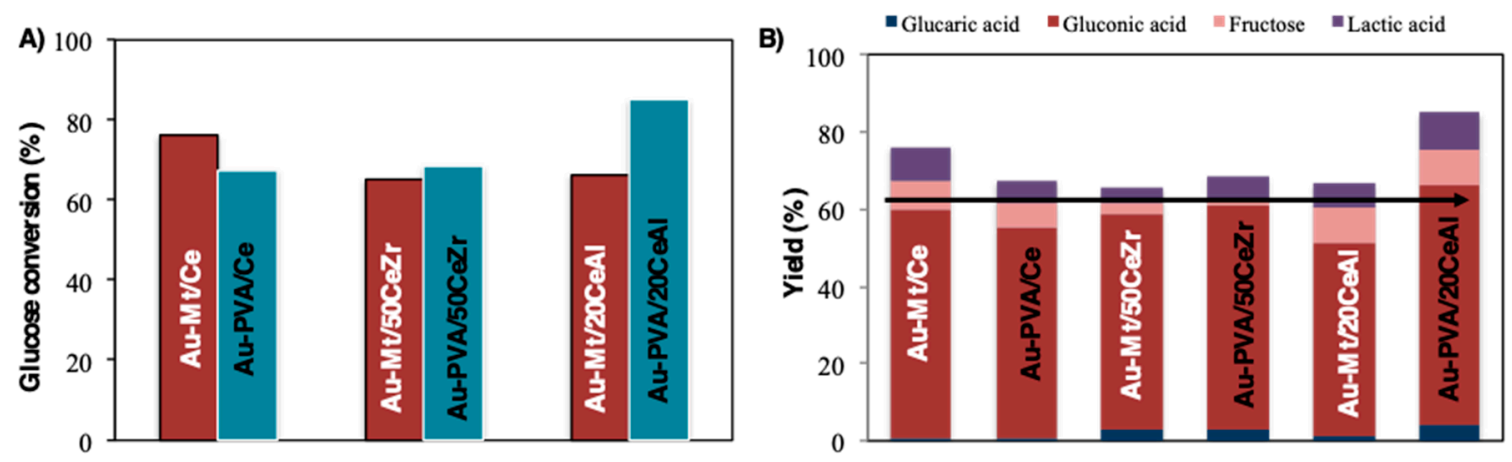

Figure 5. Glucose conversion (A) and product yields (B) as a function of support.

The glucose conversion did not follow a clear trend. However, the TOF values (calculated as mole of converted glucose per mole of exposed $\mathrm{Au}$ sites (moles $\mathrm{Au}^{*}$ dispersion) and per hour) showed that the PVA-stabilized samples were less active than the clay-stabilized materials. The observed CO-TOF values were slightly inferior to those reported for other gold catalysts [34]. As for the glucoseTOF 
values, the use of gold-stabilized colloids resulted in higher specific activity in comparison to very similar catalysts over the same supports, as presented in Table 2. It appears that this method of metal deposition was more effective, especially for the liquid phase reactions. However, the $\mathrm{Au}-\mathrm{Mt} / \mathrm{Ce}$ and $\mathrm{Au}-\mathrm{PVA} / \mathrm{Ce}$ catalysts were less active than the $\mathrm{Au} / \mathrm{C}$ systems prepared by the same colloidal immobilization method used in this study [39].

This was true for both reactions, $\mathrm{CO}$ and glucose oxidation, which means that they were influenced in the same manner. Taking into account that the variable here was the stabilizing agent and that all the samples had similar particle size, we propose two more reasons explaining this variation: (i) electronic state stabilization, and/or (ii) the presence of carbonaceous leftovers covering the active sites.

As expected, the type of support also played an important role, and the order of activity was $20 \mathrm{CeAl}>50 \mathrm{CeZr}>\mathrm{Ce}$. The activity trend did not correlate with the surface area. However, the larger pore size appeared to be beneficial to obtain higher conversion. On the other hand, a similar activity trend, previously reported for similar Au catalysts, was related to the decrease in the strength of the Lewis acid sites in the same order as the activity $(20 \mathrm{CeAl}>50 \mathrm{CeZr}>\mathrm{Ce})$ [13]. The product yield distribution was similar, suggesting that the selectivity was a function of temperature and not catalyst state, as seen in Figure 5B.

The addition of base, as seen in Figure 6, promotes glucose conversion and changes the selectivity balance whatever the nature of catalyst. An important effect of the base addition was the complete absence of gold metal leaching, observed for the spent samples, which on first sight appeared satisfactory. However, this fact and even the slight increase in glucose conversion in the base conditions did not justify their use since a decrease in the gluconic acid yield in favor of fructose formation was observed [40].
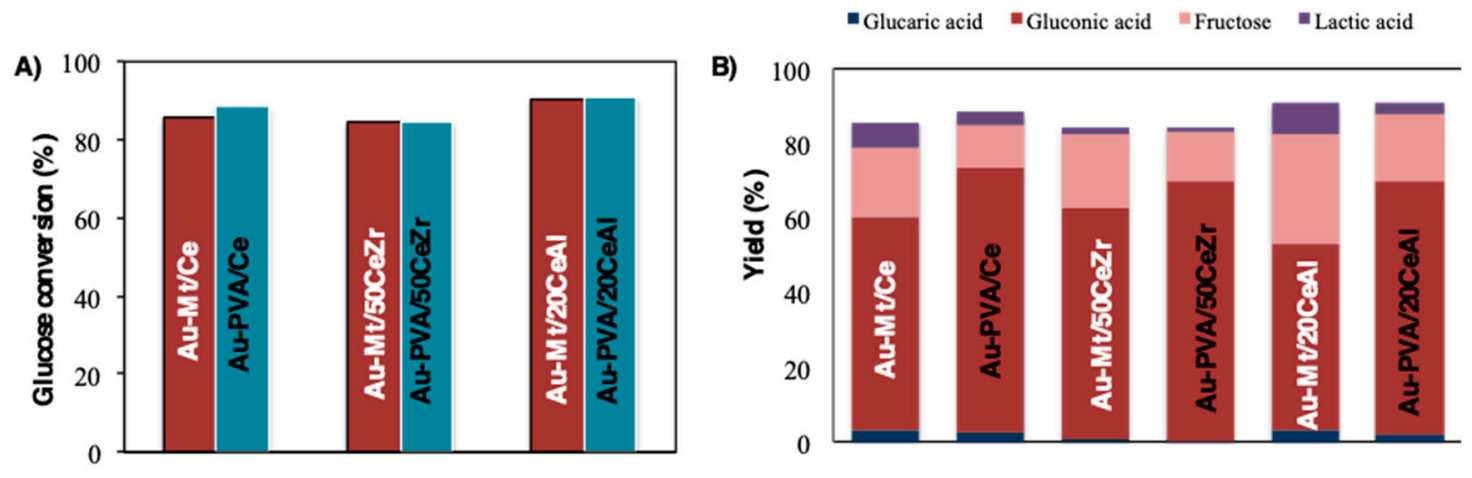

Figure 6. (A) Glucose conversion (\%) in $\mathrm{NaOH}$ presence, glucose: $\mathrm{NaOH}$ molar ratio 1:2 (600 rpm, $18 \mathrm{~h}) ;(\mathbf{B})$ yield (\%).

Four cycles of utilization were carried out over the Au-Mt/Ce catalyst with a constant glucose-to-catalyst ratio, as seen in Figure 7. This sample was selected to representing all of the samples, as a similar trend was observed in all cases. Between the cycles, the catalysts were recovered by centrifugation, washed in water and dried overnight prior to their re-utilization. A decrease in the initial activity was observed after the first cycle and remained constant afterwards. Our previous study of gold catalyst recycling in base-free reactions proposed three reasons for catalyst deactivation: (i) gold particle size, (ii) gold leaching, and (iii) catalyst surface covered with reaction intermediates [12]. The third reason was quickly discarded, and only the change of gold metal state (loadings and dispersion) was considered as the major reason for catalyst deactivation. In the case of the $\mathrm{Au}-\mathrm{Mt} / \mathrm{Ce}$ catalyst, both factors should be considered. The size of the gold particles increased to $6.8 \mathrm{~nm}$ after the first cycle, and the same was observed for the Au-PVA/Ce sample $(7 \mathrm{~nm})$. However, the excessive metal leaching detected after the first cycle (around $20 \%$ occurring between the 1 st and the 2 nd cycle and not changing after this) suggests that the probable main reason for this activity change was gold metal loss, which was also observed for the gold catalysts supported over mineral supports [13]. 


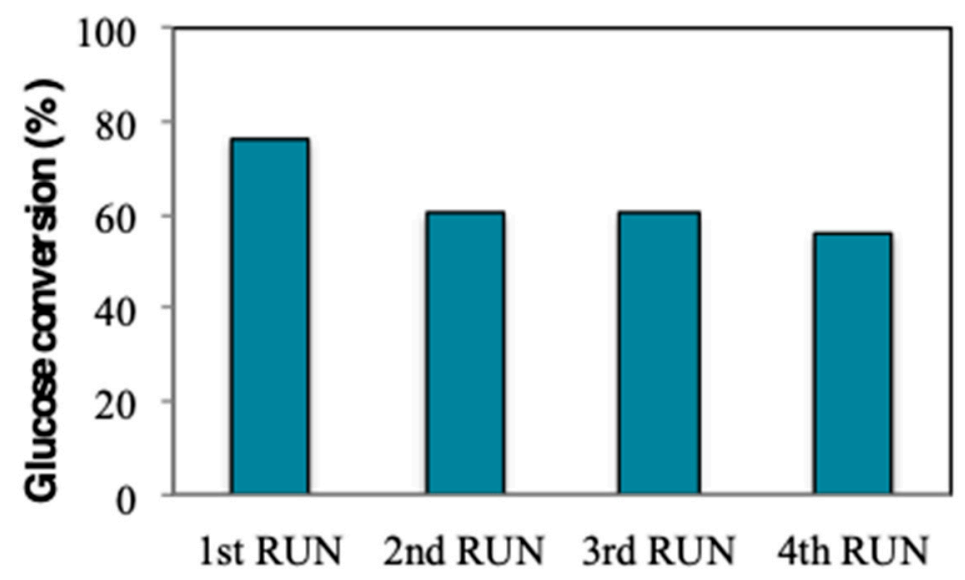

Figure 7. Reusability study over the Au-Mt/Ce catalyst.

\section{Experimental}

\subsection{Stabilizing Agents}

Polyvinylalcohol (PVA) (Sigma Aldrich, Mw 31000, San Luis, MO, USA) and natural bentonite, obtained from the Roussel deposit of Maghnia (Algeria), were the stabilizing agents.

Prior to use, the natural bentonite underwent purification by sedimentation to remove all impurities (mostly sand, feldspar and calcite). In a typical preparation, $10 \mathrm{~g}$ of bentonite were vigorously stirred in $1 \mathrm{~L}$ of distilled water for $3 \mathrm{~h}$ and left to sediment for $24 \mathrm{~h}$. A total of $2 / 3$ of the uppermost supernatant portion was then separated and dried overnight at $80{ }^{\circ} \mathrm{C}$. The purified bentonite, mainly montmorillonite, was subsequently transformed to its homoionic Na-exchanged form by treatment with $1 \mathrm{M}$ sodium chloride solution. As the stabilizer, only the $<2 \mathrm{~mm}$ fraction of Na-montmorillonite was retained. The sample label was Mt.

\subsection{Gold Catalysts}

$\mathrm{HAuCl}_{4}$ (Johnson Matthey, 49.99\%, London, UK) and $\mathrm{NaBH}_{4}$ (Sigma Aldrich, 98\%, San Luis, MO, USA) were used as gold precursor and reducing agent, respectively. Three commercial ceria-based solids were used as supports for the gold nanoparticle immobilization: $\mathrm{CeO}_{2}(20 \% \mathrm{wt}) / \mathrm{Al}_{2} \mathrm{O}_{3}$ from Sasol (denoted as 20CeAl) and pure $\mathrm{CeO}_{2}$ and $\mathrm{CeO}_{2}(50 \% \mathrm{wt}) / \mathrm{ZrO}_{2}$ sample from Daiichi Kigenso Kagaku Kogio Co., Ltd. (Osaka, Japan) (denoted as Ce and 50CeZr, respectively).

\subsubsection{Mt as Stabilizing Agent}

Catalysts with a nominal gold loading of $2 \mathrm{wt} \%$, were prepared via the colloidal route. A total of $50 \mathrm{~mL}$ of a $10^{-3} \mathrm{M} \mathrm{HAuCl}_{4}$ solution was reduced with $10 \mathrm{ml} \mathrm{NaBH} 4$ aqueous solution (1 mmol) in the presence of Mt montmorillonite $(0.5 \mathrm{~g})$ as the stabilizer. Finally, the obtained gold colloids were immobilized over the corresponding supports at a $\mathrm{pH}$ lower than its isoelectric point (4.8), with the $\mathrm{pH}$ adjusted by the addition of $0.1 \mathrm{M} \mathrm{HCl}$. After centrifugation, washing, and drying (overnight at $80{ }^{\circ} \mathrm{C}$ ) the catalysts labeled $\mathrm{Au}-\mathrm{Mt} / \mathrm{Ce}, \mathrm{Au}-\mathrm{Mt} / 50 \mathrm{CeZr}$ and $\mathrm{Au}-\mathrm{Mt} / 20 \mathrm{CeAl}$ were used directly in the reactions.

\subsubsection{PVA as Stabilizing Agent}

A similar colloidal route was used for the samples using PVA (Sigma Aldrich, Mw 31000, San Luis, MO USA) as the stabilizing agent ( $2 \mathrm{wt} \% \mathrm{Au}$, nominal value). A total of $10^{-3} \mathrm{M} \mathrm{HAuCl}_{4}$ solution was reduced with $\mathrm{NaBH}_{4}$ in presence of PVA in Au:PVA, mass ratio of 1.5:1 and the obtained colloid was immobilized over the supports. The solids were then filtered, washed and dried at $80^{\circ} \mathrm{C}$ for $24 \mathrm{~h}$ and calcined in air at $350{ }^{\circ} \mathrm{C}$ for $4 \mathrm{~h}$ with $3{ }^{\circ} \mathrm{C} / \mathrm{min}^{-1}$ heating rate. The catalysts received the labels $\mathrm{Au}-\mathrm{PVA} / \mathrm{Ce}, \mathrm{Au}-\mathrm{PVA} / 50 \mathrm{CeZr}$, and Au-PVA/20CeAl, respectively. 


\subsection{Catalytic Test}

\subsubsection{CO Oxidation}

The activity measurements were carried out at atmospheric pressure in a cylindrical stainless steel fixed bed reactor $\left(7.5 \mathrm{~mm}\right.$ inner diameter). The catalysts $(100 \mathrm{mg})$ were activated in $50 \mathrm{~mL} \mathrm{~min}^{-1}$ air flow at $300{ }^{\circ} \mathrm{C}$, for $1 \mathrm{~h}$ (heating rate of $10{ }^{\circ} \mathrm{C} \cdot \mathrm{min}^{-1}$ ). Then, the system was cooled down to $50{ }^{\circ} \mathrm{C}$ and the reactive mixture, composed of 3.4\% CO (Air Liquide, 99.997\%), and 21\% $\mathrm{O}_{2}$ (Air Liquide, 99.999\%) balanced in nitrogen, was introduced into the reactor. The total gas flow employed in the catalytic test was $42 \mathrm{~mL} / \mathrm{min}^{-1}$ corresponding to a weight hourly space velocity (WHSV) of $31.5 \mathrm{~L} \mathrm{~g}_{\text {(cat) }}{ }^{-1} \mathrm{~h}^{-1}$. The catalytic activity was measured at each temperature increase of $50{ }^{\circ} \mathrm{C}$ up to $300{ }^{\circ} \mathrm{C}$. The inlet and outlet of the reactor gas concentrations were quantified by the online gas chromatograph Agilent ${ }^{\circledR} 6890$ equipped with HPLOT Q and HP-5 columns and a TCD detector. The CO conversion was calculated according to Equation (1).

$$
\text { COconversion }=\frac{\mathrm{CO}_{\text {in }}-\mathrm{CO}_{\text {out }}}{\mathrm{CO}_{\text {in }}} \times 100
$$

where $\mathrm{CO}_{\text {in }}$ is the inlet $\mathrm{CO}$ concentration and $\mathrm{CO}_{\text {out }}$ is that of the outlet.

\subsubsection{Glucose Oxidation}

D-(+)-Glucose (anhydrous, 99\%) purchased from Alfa Aesar was used as received for the catalytic test performed in a glass batch reactor $(50 \mathrm{~mL})$ equipped with Young valve and magnetic stirrer.

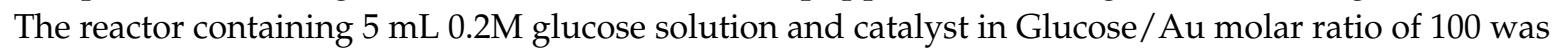
contacted and saturated with oxygen at atmospheric pressure (approximate $\mathrm{P}\left(\mathrm{O}_{2}\right)$ of $\left.0.1 \mathrm{MPa}\right)$. The reaction occurred upon constant stirring $(600 \mathrm{rpm})$ at different temperatures $\left(80{ }^{\circ} \mathrm{C}-120{ }^{\circ} \mathrm{C}\right.$ range $)$ in base free conditions as a function of time. After reaction, a $500 \mu \mathrm{L}$ aliquot from the final mixture, diluted in $500 \mu \mathrm{L}$ of MilliQ water, was immediately analyzed by HPLC, in a Varian 360-LC instrument equipped with a refractory index detector and $\mathrm{Hi}$ - Plex $\mathrm{H}$ column preheated at $40{ }^{\circ} \mathrm{C}$ using water as the mobile phase with a $0.4 \mathrm{~mL} \cdot \mathrm{min}^{-1}$ flow rate.

Conversion, selectivity and yield calculations were based on the HPLC measurements. The reported conversions were obtained after comparing the glucose concentration before and after the reaction, as shown in Equation (2). On the other hand the selectivity was calculated on the basis of the analyzed carbon moles, as described in Equation (3). Finally, the yields were calculated by Equation (4).

$$
\begin{gathered}
\text { conversion }=\frac{\left[\text { glucose }_{\mathrm{i}}-\left[\text { glucose }_{\mathrm{f}}\right.\right.}{[\text { glucose }]_{\mathrm{i}}} \times 100 \\
\text { selectivity }=\frac{\mathrm{n}_{\mathrm{i}}}{\mathrm{n}_{\mathrm{T}}} \times 100 \\
\text { Yield }=\frac{\text { conversion }}{100} \times \text { selectivity }
\end{gathered}
$$

where [glucose $_{\mathrm{i}}$ and $[\text { glucose }]_{\mathrm{f}}$ are the initial and final number of glucose moles and $\mathrm{n}_{\mathrm{i}}$ and $\mathrm{n}_{\mathrm{T}}$ are the $\mathrm{C}$ moles of the $i$ products and the total number of analyzed $\mathrm{C}$ moles.

\subsection{Characterization}

BET-specific surface areas and pore diameter, calculated by the Barrett-Joyner-Halenda (BJH) method, were obtained using the Micromeritics Tristar II equipment. The samples were outgassed before analysis at $250{ }^{\circ} \mathrm{C}$ in vacuum $2 \mathrm{~h}$ prior to $\mathrm{N}_{2}$ adsorption.

The XRD analyses were performed on an X'Pert Pro PANanalytical instrument (Almelo, The Netherlands) using CuKa radiation in the $5-80^{\circ} 2 \theta$ range with a $0.01^{\circ}$ step size and $300 \mathrm{~s}$ step time.

X-ray Fluorescence (XRF) using Panalytical AXIOS spectrometer (Almelo, The Netherlands) with an $\mathrm{Rh}$ tube as the source of radiation determined the actual gold loadings. 
The transmission electron microscopy (TEM) analysis was carried out on the TOPCON-002B apparatus (Tokyo, Japan). Prior to analysis, all samples were dispersed in ethanol and deposited on a holey carbon copper grid. The particle size distribution was estimated to be over 30 micrographs and the mean gold particle diameter was considered based on its homogeneity over an important number of particles ( $>100$ counted particles).

\section{Conclusions}

Gold nanoparticles were successfully prepared and stabilized using montmorillonite and PVA as the protecting agents. A similar particle size and distribution was observed in both cases. The catalytic activity of the samples depends strongly on the support nature. The presence of mobile oxygen species was very important for the gas phase CO oxidation. Meanwhile, the Lewis sites strength and the rate of oxygen dissolution were the predominant parameters for the glucose liquid phase oxidation. In both reactions, the use of montmorillonite as the stabilizing agent resulted in more active catalysts tentatively ascribed to a different gold electronic state and/or to the presence of carbonaceous leftovers influencing the gold/support interaction and subsequent $\mathrm{CO}$ /glucose adsorption step.

Author Contributions: Conceptualization, S.I.; methodology, F.A.; validation, S.I., F.A. and M.A.C.; investigation, M.C. and C.M.-S.; resources, J.A.O. and M.A.C.; writing-original draft preparation, S.I.; writing-review and editing, M.A.C.; visualization, S.I. and M.A.C.; supervision, J.A.O.; funding acquisition, J.A.O.

Funding: This research received no external funding.

Acknowledgments: Meriem Chenouf acknowledges the Algerian Ministry of Higher Education and Scientific Research (MESRS) and the University of Seville, Spain (Program for international students mobility, $3^{\text {er }}$ Plan Propio de Docencia).

Conflicts of Interest: The authors declare no conflict of interest.

\section{References}

1. Chheda, J.N.; Huber, G.W.; Dumesic, J.A. Liquid-phase catalytic processing of biomass-derived oxygenated hydrocarbons to fuels and chemicals. Angew. Chem. Int. Ed. 2007, 46, 7164-7183. [CrossRef] [PubMed]

2. Serrano-Ruiz, J.C.; Luque, R.; Sepúlveda-Escribano, A. Transformations of biomass-derived platform molecules: From high added-value chemicals to fuels via aqueous-phase processing. Chem. Soc. Rev. 2011, 40, 5266-5281. [CrossRef] [PubMed]

3. Ishida, T.; Kinoshita, N.; Okatsu, H.; Akita, T.; Takei, T.; Haruta, M. Influence of the support and the size of gold clusters on catalytic activity for glucose oxidation. Angew. Chem. Int. Ed. 2008, 47, 9265-9268. [CrossRef] [PubMed]

4. Mirescu, A.; Prüße, U. Selective glucose oxidation on gold colloids. Catal. Commun. 2006, 7, 11-17. [CrossRef]

5. Rautiainen, S.; Lehtinen, P.; Vehkamäki, M.; Niemelä, K.; Kemell, M.; Heikkilä, M.; Repo, T. Microwave-assisted base-free oxidation of glucose on gold nanoparticle catalysts. Catal. Commun. 2016, 74, 115-118. [CrossRef]

6. Climent, M.J.; Corma, A.; Iborra, S. Converting carbohydrates to bulk chemicals and fine chemicals over heterogeneous catalysts. Green Chem. 2011, 13, 520-540. [CrossRef]

7. Hustede, E.S.H.; Haberstroh, H.J.; Schinzig, E. Ullmann's Encyclopedia of Industrial Chemistry; Wiley-VCH Verlag GmbH \& Co. KGaA: Weinheim, Germany, 2000.

8. Wojcieszak, R.; Cuccovia, I.M.; Silva, M.A.; Rossi, L.M. Selective oxidation of glucose to glucuronic acid by cesium-promoted gold nanoparticle catalyst. J. Mol. Catal. A Chem. 2016, 422, 35-42. [CrossRef]

9. Biella, S.; Prati, L.; Rossi, M. Selective oxidation of D-glucose on gold catalyst. J. Catal. 2002, 206, $242-247$. [CrossRef]

10. Amarasekara, A.S.; Green, D.; McMillan, E. Efficient oxidation of 5-hydroxymethylfurfural to 2,5-diformylfuran using Mn (III)-salen catalysts. Catal. Commun. 2008, 9, 286-288. [CrossRef]

11. Saliger, R.; Decker, N.; Prüße, U. D-Glucose oxidation with $\mathrm{H}_{2} \mathrm{O}_{2}$ on an $\mathrm{Au} / \mathrm{Al} 2 \mathrm{O} 3$ catalyst. Appl. Catal. B Environ. 2011, 102, 584-589. [CrossRef]

12. Megías-Sayago, C.; Bobadilla, L.F.; Ivanova, S.; Penkova, A.; Centeno, M.A.; Odriozola, J.A. Gold catalyst recycling study in base-free glucose oxidation reaction. Catal. Today 2018, 301, 72-77. [CrossRef] 
13. Megías-Sayago, C.; Ivanova, S.; López-Cartes, C.; Centeno, M.A.; Odriozola, J.A. Gold catalysts screening in base-free aerobic oxidation of glucose to gluconic acid. Catal. Today 2017, 279, 148-154. [CrossRef]

14. Miedziak, P.J.; Alshammari, H.; Kondrat, S.A.; Clarke, T.J.; Davies, T.E.; Morad, M.; Morgan, D.J.; Willock, D.J.; Knight, D.W.; Taylor, S.H.; et al. Base-free glucose oxidation using air with supported gold catalysts. Green Chem. 2014, 16, 3132-3141. [CrossRef]

15. Qi, P.; Chen, S.; Chen, J.; Zheng, J.; Zheng, X.; Yuan, Y. Catalysis and reactivation of ordered mesoporous carbon-supported gold nanoparticles for the base-free oxidation of glucose to gluconic acid. ACS Catal. 2015, 5, 2659-2670. [CrossRef]

16. Prüße, U.; Herrmann, M.; Baatz, C.; Decker, N. Gold-catalyzed selective glucose oxidation at high glucose concentrations and oxygen partial pressures. Appl. Catal. A Gen. 2011, 406, 89-93. [CrossRef]

17. Schrekker, H.S.; Gelesky, M.A.; Stracke, M.P.; Schrekker, C.M.L.; Machado, G.; Teixeira, S.R.; Rubim, J.C.; Dupont, J. Disclosure of the imidazolium cation coordination and stabilization mode in ionic liquid stabilized gold (0) nanoparticles. J. Colloid Interface Sci. 2007, 316, 189-195. [CrossRef] [PubMed]

18. Shang, K.; Geng, Y.; Xu, X.; Wang, C.; Lee, Y.I.; Hao, J.; Liu, H.G. Unique self-assembly behavior of a triblock copolymer and fabrication of catalytically active gold nanoparticle/polymer thin films at the liquid/liquid interface. Mater. Chem. Phys. 2014, 146, 88-98. [CrossRef]

19. Zhang, W.; Liu, B.; Zhang, B.; Bian, G.; Qi, Y.; Yang, X.; Li, C. Synthesis of monodisperse magnetic sandwiched gold nanoparticle as an easily recyclable catalyst with a protective polymer shell. Colloids Surf. A Physicochem. Eng. Asp. 2015, 466, 210-218. [CrossRef]

20. Boronat, M.; Corma, A.; Illas, F.; Radilla, J.; Ródenas, T.; Sabater, M.J. Mechanism of selective alcohol oxidation to aldehydes on gold catalysts: Influence of surface roughness on reactivity. J. Catal. 2011, 278, 50-58. [CrossRef]

21. Ivanova, S.; Pitchon, V.; Zimmermann, Y.; Petit, C. Preparation of alumina supported gold catalysts: Influence of washing procedures, mechanism of particles size growth. Appl. Catal. A Gen. 2006, 298, 57-64. [CrossRef]

22. Zanella, R.; Giorgio, S.; Shin, C.H.; Henry, C.R.; Louis, C. Characterization and reactivity in CO oxidation of gold nanoparticles supported on $\mathrm{TiO}_{2}$ prepared by deposition-precipitation with $\mathrm{NaOH}$ and urea. J. Catal. 2004, 222, 357-367. [CrossRef]

23. Agarwal, S.; Ganguli, J.N. Selective hydrogenation of monoterpenes on rhodium (0) nanoparticles stabilized in Montmorillonite K-10 clay. J. Mol. Catal. A Chem. 2013, 372, 44-50. [CrossRef]

24. Sarmah, P.P.; Dutta, D.K. Stabilized Rh0-nanoparticles-Montmorillonite clay composite: Synthesis and catalytic transfer hydrogenation reaction. Appl. Catal. A Gen. 2014, 470, 355-360. [CrossRef]

25. Eren, E.; Afsin, B. An investigation of $\mathrm{Cu}$ (II) adsorption by raw and acid-activated bentonite: A combined potentiometric, thermodynamic, XRD, IR, DTA study. J. Hazard. Mater. 2008, 151, 682-691. [CrossRef]

26. Sarma, G.K.; Sen Gupta, S.; Bhattacharyya, K.G. Adsorption of crystal violet on raw and acid-treated montmorillonite, K10, in aqueous suspension. J. Environ. Manag. 2016, 171, 1-10. [CrossRef] [PubMed]

27. Zhao, H.; Zhou, C.H.; Wu, L.M.; Lou, J.Y.; Li, N.; Yang, H.M.; Tong, D.S.; Yu, W.H. Catalytic dehydration of glycerol to acrolein over sulfuric acid-activated montmorillonite catalysts. Appl. Clay Sci. 2013, 74, 154-162. [CrossRef]

28. Letaief, S.; Grant, S.; Detellier, C. Phenol acetylation under mild conditions catalyzed by gold nanoparticles supported on functional pre-acidified sepiolite. Appl. Clay Sci. 2011, 53, 236-243. [CrossRef]

29. Álvarez, A.; Moreno, S.; Molina, R.; Ivanova, S.; Centeno, M.A.; Odriozola, J.A. Gold supported on pillared clays for CO oxidation reaction: Effect of the clay aggregate size. Appl. Clay Sci. 2012, 69, 22-29. [CrossRef]

30. Carriazo, J.G.; Martínez, L.M.; Odriozola, J.A.; Moreno, S.; Molina, R.; Centeno, M.A. Gold supported on Fe, $\mathrm{Ce}$, and Al pillared bentonites for CO oxidation reaction. Appl. Catal. B Environ. 2007, 72, 157-165. [CrossRef]

31. Martínez, L.M.T.; Domínguez, M.I.; Sanabria, N.; Hernández, W.Y.; Moreno, S.; Molina, J.A.; Odriozola, J.A.; Centeno, M.A. Deposition of Al-Fe pillared bentonites and gold supported Al-Fe pillared bentonites on metallic monoliths for catalytic oxidation reactions. Appl. Catal. A Gen. 2009, 364, 166-173. [CrossRef]

32. Zhu, L.; Letaief, S.; Liu, Y.; Gervais, F.; Detellier, C. Clay mineral-supported gold nanoparticles. Appl. Clay Sci. 2009, 43, 439-446. [CrossRef]

33. Carabineiro, S.A.C.; Silva, A.M.T.; Draić, G.; Tavares, P.B.; Figueiredo, J.L. Gold nanoparticles on ceria supports for the oxidation of carbon monoxide. Catal. Today 2010, 154, 21-30. [CrossRef]

34. Grunwaldt, J.-D.; Kiener, C.; Wögerbauer, C.; Baiker, A. Preparation of supported gold catalysts for low-temperature CO oxidation via "size-controlled" gold colloids. J. Catal. 1999, 181, 223-232. [CrossRef] 
35. Ivanova, S.; Pitchon, V.; Petit, C.; Caps, V. Support effects in the gold-catalyzed preferential oxidation of CO. ChemCatChem 2010, 2, 556-563. [CrossRef]

36. Ivanova, S.; Pitchon, V.; Petit, C. Application of the direct exchange method in the preparation of gold catalysts supported on different oxide materials. J. Mol. Catal. A Chem. 2006, 256, 278-283. [CrossRef]

37. Madier, Y.; Descorme, C.; Le Govi, A.M.; Duprez, D. Oxygen mobility in $\mathrm{CeO}_{2}$ and $\mathrm{Ce} x \mathrm{Zr}(1-\mathrm{x}) \mathrm{O}_{2}$ compounds: Study by CO transient oxidation and $18 \mathrm{O} / 16 \mathrm{O}$ isotopic exchange. J. Phys. Chem. B 1999, 103, 10999-11006. [CrossRef]

38. Comotti, M.; Pina, C.; Della Rossi, M. Mono- and bimetallic catalysts for glucose oxidation. J. Mol. Catal. A Chem. 2006, 251, 89-92. [CrossRef]

39. Megías-Sayago, C.; Santos, J.L.; Ammari, F.; Chenouf, M.; Ivanova, S.; Centeno, M.A.; Odriozola, J.A. Influence of gold particle size in Au/C catalysts for base-free oxidation of glucose. Cat. Today 2018, 306, 183-190. [CrossRef]

40. Kooyman, C.; Vellenga, K.; De Wilt, H.G.J. The isomerization of D-glucose into D-fructose in aqueous alkaline solutions. Carbohydr. Res. 1977, 54, 33-44. [CrossRef]

(C) 2019 by the authors. Licensee MDPI, Basel, Switzerland. This article is an open access article distributed under the terms and conditions of the Creative Commons Attribution (CC BY) license (http://creativecommons.org/licenses/by/4.0/). 